\title{
Daylighting and Energy Performance of PVSDs;
}

\author{
Testing the potential of retrofitting Educational Spaces in Cairo, Egypt
}

\author{
Mai A. Marzouk \\ Department of Architecture \\ Faculty of Engineering - Ain Shams University in Cairo \\ Cairo, Egypt \\ Mai_Adel_28@eng.asu.edu.eg
}

\author{
Mostafa Atwa \\ Architecture and Urban Design Program \\ Faculty of Engineering and Material Sciences - The German University in Cairo \\ Cairo, Egypt \\ DOI: $10.31364 / S C I R J / v 8 . i 8.2020 . P 0820796$ \\ http://dx.doi.org/10.31364/SCIRJ/v8.i8.2020.P0820796
}

\begin{abstract}
Nowadays, many countries are putting in efforts to reduce the energy consumption of buildings by adopting initiatives aimed at the development of net-zero energy buildings. These initiatives endorsed the growing interest in using building integrated photovoltaics (BIPV) as a means of achieving their aims. The adoption of $\mathrm{PV}$ in new or existing buildings does not only help reduce energy demand of the buildings but also increase the energy supply from renewable sources. In addition, in hot arid climates, where solar irradiation reaches its highest levels, solar protection through shading devices is required and effective for buildings' proper functionality. Consequently, integrating PVs as shading devices could result in the double benefit of electricity production coupled with solar protection. In this paper, the integration of $P V$ as a shading element was quantitatively studied. The study was conducted on an educational space that is highly glazed, which results in excessive overheating and visual discomfort. Therefore, the approach of improving the energy efficiency of the space by applying a PVSD on the south and east façades was adopted at 4 different tilt angles $\left(-15^{\circ},-20^{\circ},-25^{\circ}\right.$ and $\left.-30^{\circ}\right)$ for each orientation. The study aims to achieve the optimal balance between daylight availability, energy consumption and generated energy of the PV surfaces. The study was conducted using Rhinoceros, Grasshopper 3D, DIVA for Rhino and ArchSIM software for modelling purposes and simulation processes to reach conclusions about the optimum tilt angle and orientation of PVSD for the case of Cairo.
\end{abstract}

Keywords- Renewable Energy, Building Integrated Photovoltaics, Photovoltaic Shading Devices, Daylighting

\section{I.INTRODUCTION}

Building Integrated Photovoltaics (BIPVs) are becoming a hot topic that is gaining a lot of attention lately. In a country like Egypt with high potential accompanied by ambition of upscaling solar energy generation from the abundant sun exposure, such a technology becomes of special importance. For it is not only a great step on the way of having more sustainable buildings but also for adding the energy generation component to the basic building features, a huge added value. According to Zhang et al. (2018), the BIPVs include PV panels into the different building components and are divided into four main categories as shown in Fig. (1); PV facades, PV roofs, PV windows and PV sunshades or what is called the Photovoltaic shading devices (PVSD); an easily applied retrofitting measure that is still poorly tackled in literature.

The hot arid climate of Cairo necessitates a lot of environmental measures to be taken into consideration in the buildings' design to ensure the energy efficiency as well as achieving the visual and thermal comfort of occupants. However, a lot of our recently built buildings have completely overlooked this environmental dimension. We have been occupying buildings with extensive curtain wall facades that are overly daylit and would act as huge greenhouses if it were not for the Air conditioning systems. This results in spaces that fail to achieve their main function of securing comfort levels for their occupants. This also creates spaces that are environmentally inefficient due to the high levels of energy consumption to compensate for the poor design decisions. Accordingly, in many cases such shading devices are highly needed to be retrofitted into buildings to create the double effect of shading; reducing glare and reducing heat gain resulting in lower energy consumption. Integrating PV panels to these shading devices adds the extra dimension of improving the building function and behavior while generating electricity as well. The PVSDs' productivity and efficiency in the Cairene context needed to be tested to finally harness the wasted solar potential of Cairo's sunny dry weather. The Global horizontal irradiation (GHI) in Cairo has an annual average of 2,000-2,450 kWh/m2 as shown in Fig. (2) (Marzouk, 2016; Solargis, 2016; Davies et al., 2015). Such potential is very high in comparison to the worldwide average which is $1500 \mathrm{kWh} / \mathrm{m} 2$ per year. The average number of sunlight hours throughout the year in Cairo is equal to around $9.25 \mathrm{~h} /$ day (Marzouk, 2016).

This paper focuses on analyzing the impact of retrofitting PVSD into a case study building to solve a real-world problem faced by its occupants.

\section{OBJECTIVES}

The paper aims at investigating the performance of PVSD mounted on the facades of an actual educational building in a 
University campus in Cairo. It focuses on achieving daylighting efficiency and energy loads reduction through a daylighting simulation optimization approach focusing on two main parameters of PVSD; orientation and tilt angle. The paper then culminates this analysis by quantifying the amount of energy generated by PV panels in the different orientations to reach a conclusion about the best-case scenario that balances daylighting efficiency, energy loads reduction and energy generation potential.

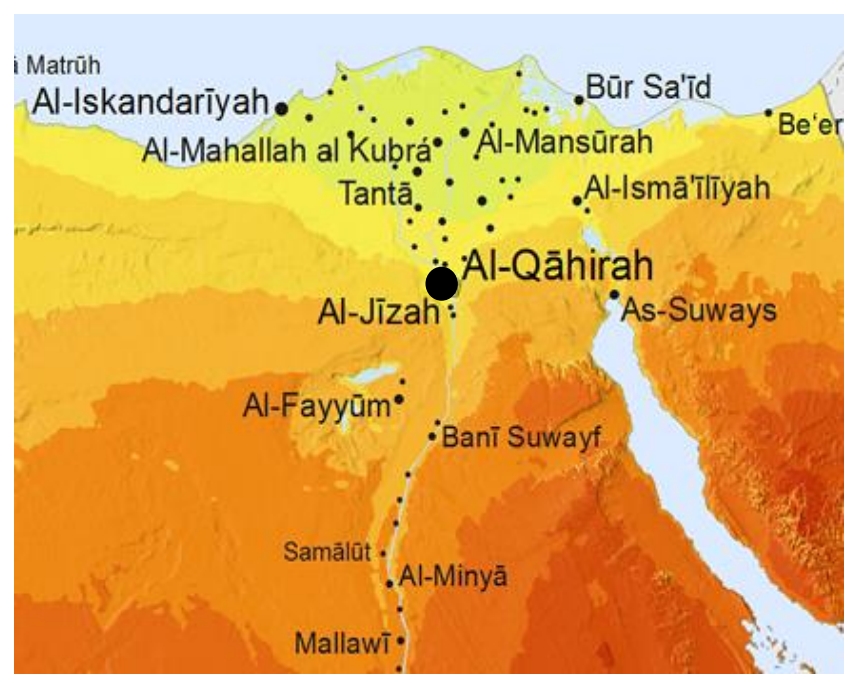

Fig. 1. Global Horizontal Irradiation of Cairo. source: (Solargis.info, 2014)

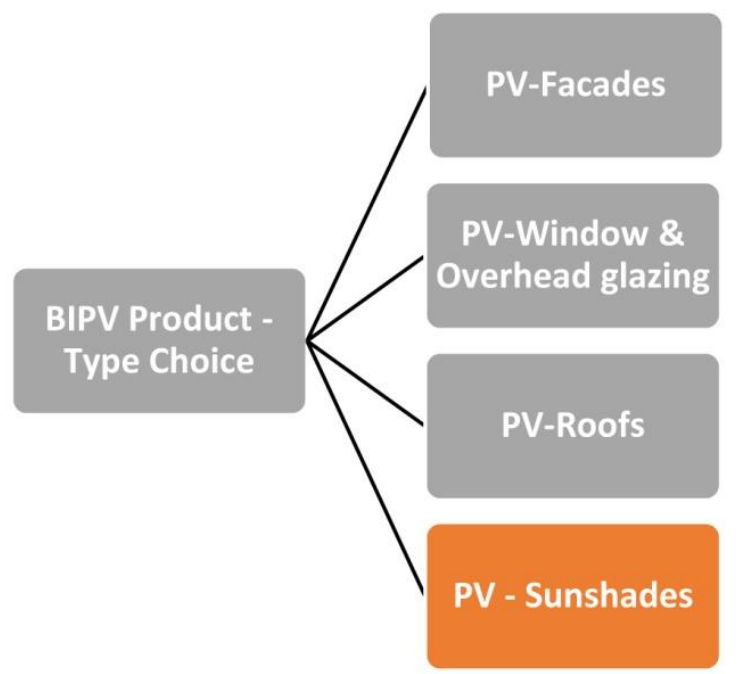

Fig. 2. Types of BIPV Products. Source: Authors based on (Zhang et al., 2018)

\section{LITERATURE REVIEW}

PV panels integration in buildings (BIPVs) is a current hot topic. Multiple papers and researches were concerned with studying the different types of BIPV systems and simulating their various impacts on improving our buildings.

In a study by ( $\mathrm{Li}$ et al., 2017), the optimum tilt angle of PVSD system was tested in different climatic zones of China. The study aimed at creating a comprehensive theoretical background for studying the integration of PV systems as shading devices to the building, by studying the impact of optimum annual and monthly tilt angles. It turned out that following the monthly tilt angles provide better results than the annual ones. They also compared different orientations of the windows onto which PVSDs are mounted. For the case of
China, it became obvious from the results that the south orientation achieves the highest results of energy consumption reduction and energy saving compared to the east and west facades. They came to a conclusion about the optimum tilt angles for 5 Chinese cities and they ranged from $35^{\circ}$ to $60^{\circ}$.

In a more contextual study by (Farrag and Omran, 2017) done on a case study in Egypt, they focused more on analyzing the amount of energy generated by the system and the corresponding reduction in emissions through its application on a single family house in one of the new urban communities in the suburbs of Giza city. The performance of PV windows implemented in the south façade of the building at different tilt angles with the vertical axis was studied to have different scenarios of exposure to solar radiation. The total annual energy produced from the vertical and titled PV systems is $24,943 \mathrm{kWh}$. This amount covers the needed energy consumption of the house that has an average of $2039.5 \mathrm{kWh}$ and peak of $4125 \mathrm{kWh}$ in the month of August. Thus, the system supplies $8,445.6 \mathrm{kWh}$ of surplus clean energy to the grid during 8 months of the year showing the extent of great potential of BIPVs application in Egypt.

\section{METHODOLOGY}

\section{A. Building Description}

The chosen case study for this paper is educational facility building in the German University campus in Cairo at latitude of $29^{\circ}$ and longitude of $31^{\circ}$ as shown in Fig. (3). The building has many design downsides reflected in the highly glazed façade with no consideration of building orientation. A realworld problem was identified by the users of the Architectural studio spaces in the last floor of the building. They reported very high levels of glare due to the excessive direct sunlight entering from curtain walls in the southern and eastern facades as well as the excessive overheating during summer as shown in Fig. (4). Consequently, users of the space close the curtains and turn on artificial lighting and A.C units to maintain moderate, well distributed heat and lighting conditions inside the space (Atwa and Mohamed, 2017). The building parameters and characteristics are shown in table (1).

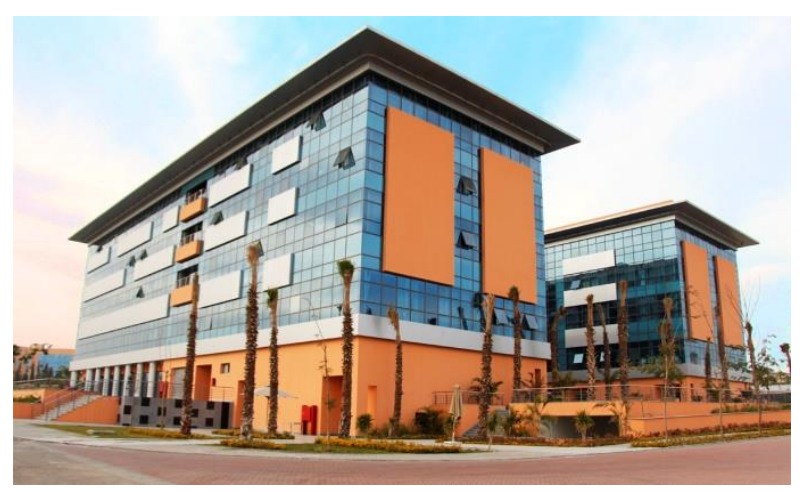

Fig. 3. The GUC D- Building (Southern and Eastern Facades of Architecture and Urban Design Program Building). 


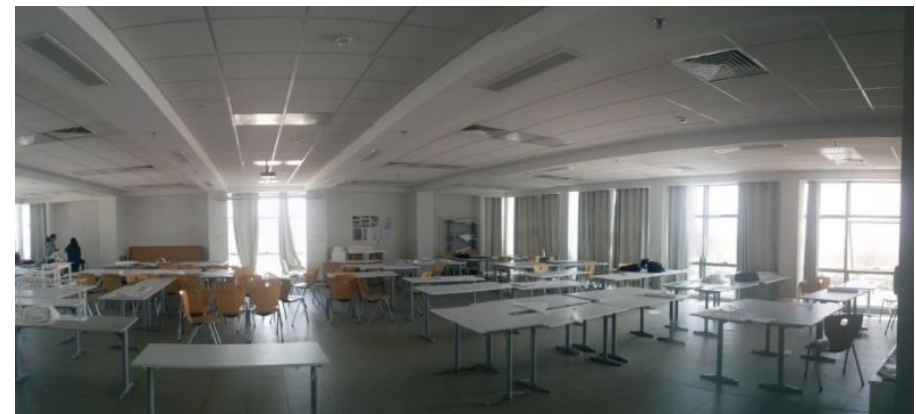

Fig. 4. The Case Study Space Inner View (The Educational Design Studio inside the GUC D- Building)

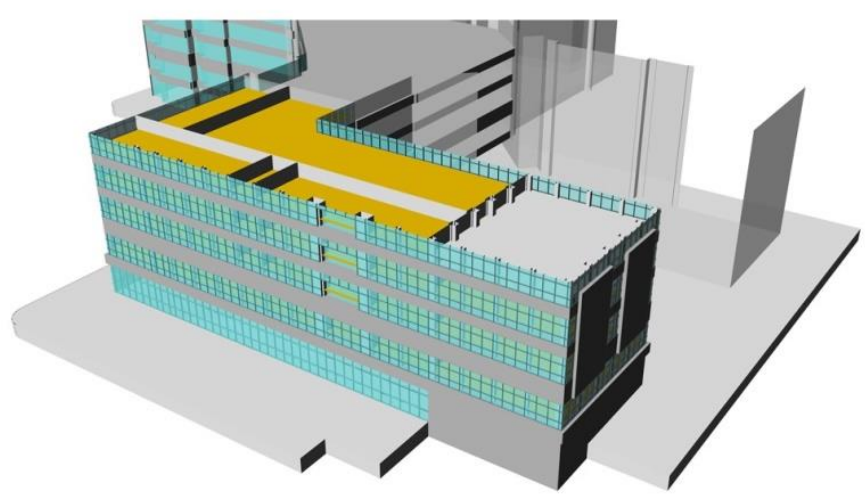

Fig. 5. The Case Study Building Model. Source: Authors

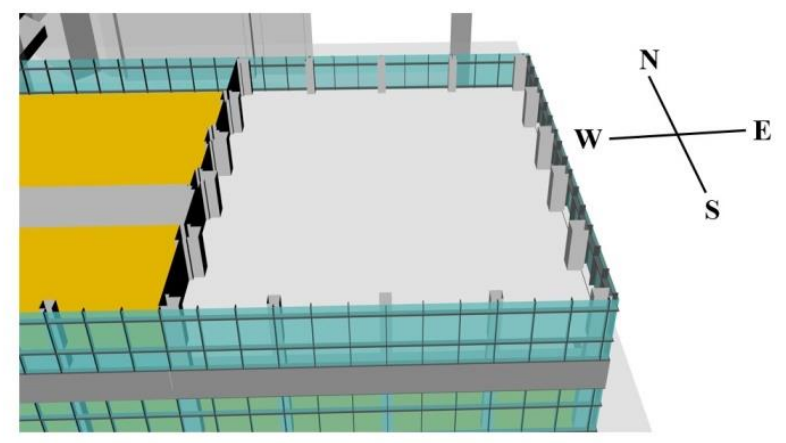

Fig. 6. The Case Study Space Model. Source: Authors

\section{B. Simulation Software}

The evaluation criteria of phase one was based on LEED V4 minimum requirements using the IES approved metrics; Spatial Daylight Autonomy (sDA 300/50\%) and Annual Sunlight Exposure (ASE 1000/250hr) (IES, 2012). LEED V4 require minimum values of $55 \%$ for the sDA metric and no more than $10 \%$ of ASE values (USGBC, 2014) (Heschong et.al. 2012).

Based on the methodology, the simulation software tools were selected. Rhinoceros 5.0 and Grasshopper 3D were the utilized modelling software tools. Additionally, the daylight simulation process was conducted through DIVA 4.0 for Rhino, which is a simulation interface that couples daylight simulation engines; Radiance and DAYSIM. While, energy simulation process and PV output calculation were processed through ArchSIM for Grasshopper that uses Energy Plus as a simulation engine.

TABLE I. CASE Study BUILding PARAMETERs. SOURCE: AutHors

\begin{tabular}{|l|l|}
\hline Space Parameters & \\
\hline Space area (m2) & $285 \mathrm{~m} 2$ \\
\hline Wall & $\begin{array}{l}\text { Material: Medium Colored walls. } \\
\text { Reflectance: } 50 \%\end{array}$ \\
\hline Ceiling & $\begin{array}{l}\text { Material: White Colored Ceiling. } \\
\text { Reflectance: } 90 \%\end{array}$ \\
\hline Floor & $\begin{array}{l}\text { Material: Generic Floor. } \\
\text { Reflectance:20\% }\end{array}$ \\
\hline Window parameters & $50.7 \mathrm{~m} 2$ \\
\hline $\begin{array}{l}\text { Curtain wall in south } \\
\text { area }\end{array}$ & $42 \mathrm{~m} 2$ \\
\hline $\begin{array}{l}\text { Curtain wall in south } \\
\text { area }\end{array}$ & $1 \mathrm{~m} \times 2 \mathrm{~m}$ \\
\hline PV Parameters & 0.15 \\
\hline Panels Dimensions & 0.8 \\
\hline Panels Efficiency & $132 \mathrm{~m} 2$ \\
\hline Effective Area of & \\
\hline $\begin{array}{l}\text { Total Area on both } \\
\text { facades }\end{array}$ & \\
\hline
\end{tabular}

\section{Simulation Process and Phases}

To solve the problem of glare and excessive heat gain that is translated into elevated levels of energy consumption, it was thought to test the impact of mounting PVSD on the curtain walls of the two most critical facades of the space. The energy generation potential will then be tested to know the extent of its impact for such a heavy-use educational building.

The paper tackles the case study problem on two phases. Phase one adopts the daylighting optimization approach to test the capacity of titled PVSDs (Photovoltaic Shading Devices) to improve daylighting quality and reduce glare in the space. It also tests the impact of their implementation on energy consumption reduction through reducing the needed cooling loads as a result of avoiding solar heat gain. Two main parameters of shading devices were considered in this paper. The first is the facade orientation since the space has curtain walls on the north, east and south facades. The second is the shading device tilt angle measured from the horizontal where it has the biggest impact on the shading effect and daylighting efficiency improvement.

In this phase, the paper compares the impact of mounting PVSDs on the south and east facades of the space since they are exposed to the highest solar radiation. It aims at identifying which façade will have the higher impact when being shaded by titled shading elements of width $2 \mathrm{~m}$. Four tilt angles were tested for each façade as follows; $-15^{\circ},-20^{\circ},-25^{\circ}$ and $-30^{\circ}$ as shown in Fig. (5). These angles were chosen specifically since they represent the optimal tilt angles (range from $15^{\circ}$ to $30^{\circ}$ ) for Cairo since it lies at latitude of average $30^{\circ}$ (El Zayat,2016; Ghoneima,2016). When applying these angles on both facades, a matrix of 16 scenarios of tilt angles combinations was produced and simulated to reach the optimum scenario of the integration of both facades. For the daylight analysis, the Spatial Daylight Autonomy (sDA) and the Annual Sun Exposure (ASE) metrics were used as will be explained in the results. Phase two is concerned with the quantification of energy generation potential. Energy generated by PV panels in both orientations for the different tilt angles was calculated. The best-case scenario is that achieves the best performance in both phases.

The studied metrics covered daylighting and shading aspects, energy consumption reduction aspect as well as energy generation aspect. For the daylight analysis, Spatial 
Daylight Autonomy (sDA) and Annual Sun Exposure (ASE) metrics were used. While for estimating the impact of shading on the improvement of thermal comfort and cooling and heating loads reduction, i.e. energy consumption reduction, the annual energy demand for cooling and heating was calculated in $\mathrm{kWh}$. The simulation of the amount of energy generated by the PV panels was done for both facades and across all the 16 scenarios of tilt angle to reach the optimum position in terms of maximum solar radiation and maximum energy generation.

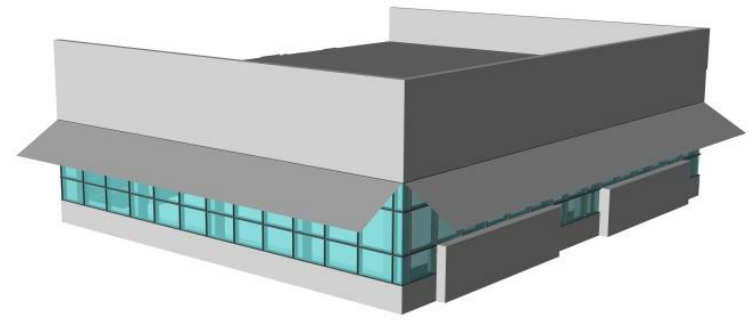

Fig. 7. Case Study model with tilted PVSD on both facades. Source: Authors

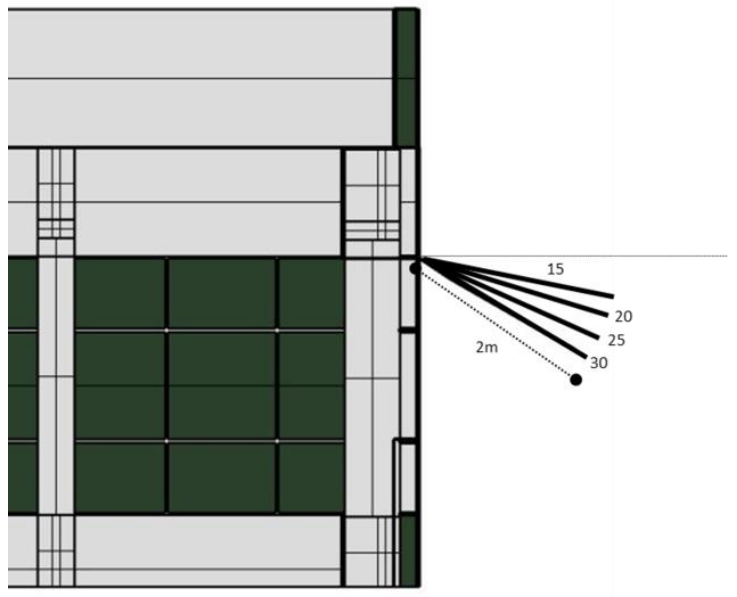

Fig. 8. Case Study section with tilted PVSD on both facades. Source: Authors

\section{RESULTS AND DISCUSSION}

\section{A. Phase 1 Results:}

For the 16 case study scenarios, the Spatial Daylight Autonomy (sDA300,50 \%) and Annual Sun Exposure (ASE1000, 250h) were calculated. Spatial Daylight Autonomy represents the percentage of space floor area that receives 300 Lux or more for at least $50 \%$ of the annual hours of space occupation. This parameter indicates if the space receives enough daylight to perform its function and be considered as a daylit space (Konis and Selkowitz, 2017). The result of sDA300,50\% shows no considerable difference between the 16 cases, where it ranges from $98.5 \%$ to $98.9 \%$ of the space receiving sufficient daylight. An sDA value starting from $75 \%$ is considered as a well daylit space that is comfortable for users (Wymelenberg and Mahić, 2018). Obviously, the high percentages achieved indicates a space with high level of natural daylight from both facades even after mounting the shading devices. The percentage did not differ much from the base case scenario; thus, the shading devices do not obstruct the natural daylight penetration.
The least percentage was achieved by the configuration of case (4.4) which combines $\left(-30^{\circ}\right)$ tilted PV panels on the south façade and $\left(-30^{\circ}\right)$ tilted panels on the east façade. The $98.5 \%$ in this case reflects the impact of shading by the highest tilt angles on both sides where it allows the least amount of daylight into the space.

The high result of sDA300,50\% was expected due to the large-sized windows on three facades of the space. However, the real problem, which is the main driver behind choosing the case study, is the excessive glare created by this high level of direct sunlight penetration into the space as indicated by the ASE1000, 250h results.

ASE1000, 250h represents the percentage of the space floor area that receives 1000 Lux or more for at least 250 hours of space occupation annually (Konis and Selkowitz, 2017). It indicates the percentage of the space receiving excess direct sunlight causing glare and discomfort level. ASE1000, $250 \mathrm{~h}$ for the base case reached $20.6 \%$ which is a very high percentage since spaces with an ASE1000, 250h of more than $10 \%$ are considered to have "Unsatisfactory Visual Comfort" (Konis and Selkowitz, 2017). All the other simulated cases fall within the "nominally acceptable" (less than 7\%) and the "clearly accepted" (less than 3\%) zones indicating the huge drop in glare levels and visual discomfort as a result of using the different combination of PVSDs on both facades. The optimum ASE1000, 250h result is achieved by case (4.4) of ($30^{\circ}$ ) tilt angle on both facades.

Overlaying the results of both the sDA and ASE shows that the case study scenario with the highest tilt angle from the horizontal in both orientations (south and east) achieves the best results. It allows enough sunlight to enter to ensure a well daylit space, but at the same time reduce the glare accompanied with the direct sunlight through its shading effect.

\section{Daylighting Simulation Results}

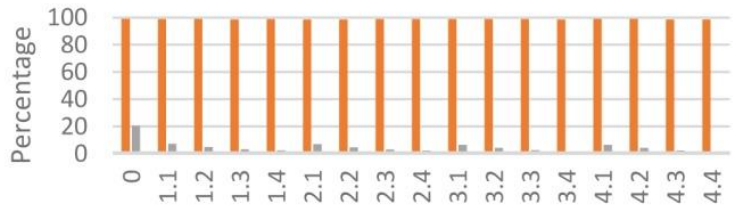

Case Study Scenarios

$\square \mathrm{sDA} \square \mathrm{ASE}$

Fig. 9. sDA and ASE results for the 16 case study scenarios. Source: Authors

As for the achieved reductions in the energy loads for both cooling and heating, all the 16 case study scenarios managed to reduce the energy loads in comparison to the base case. The base case showed an annual energy load of cooling and heating reaching 104,874 $\mathrm{kWh}$. The highest reduction in the total energy loads is also achieved by case (4.4) upon mounting the PVSD at tilt angle of $\left(-30^{\circ}\right)$ in both orientations. This result complements the sDA300,50\% and ASE1000, 250h results explained earlier reaching a conclusion that this case achieves the best daylighting efficiency as well as the best energy loads reduction.

TABLE II. COMPARISON BETWEen CASE (0) AND CASE (4.4). SOURCE: AUTHORS 

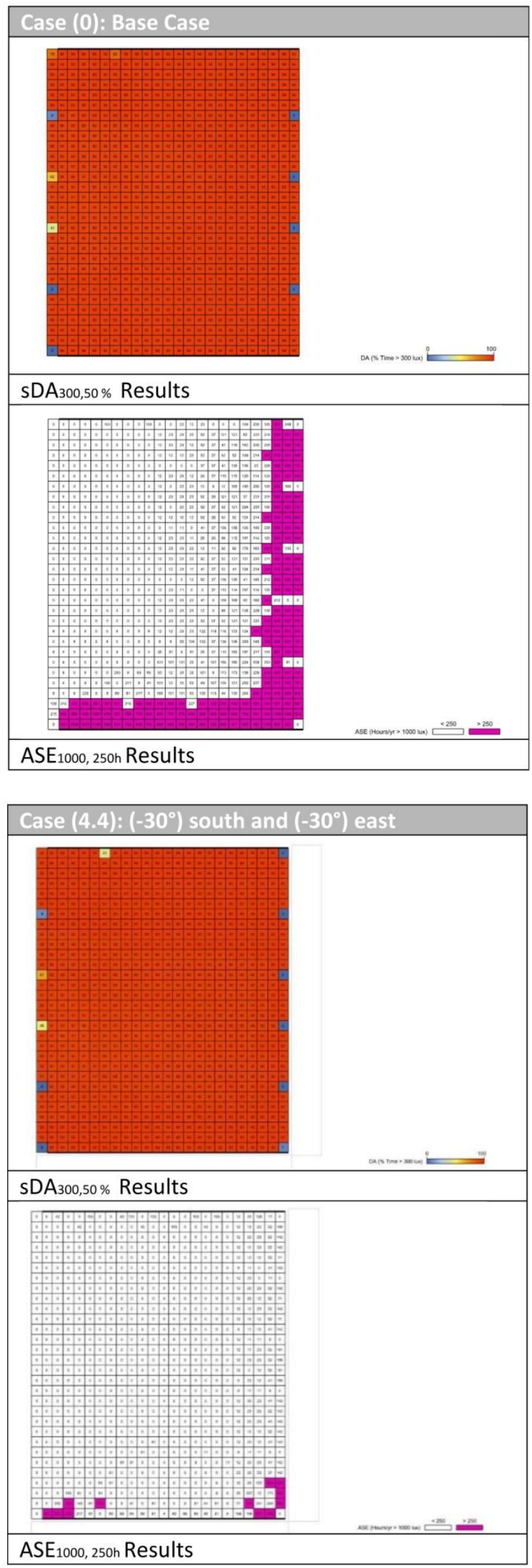

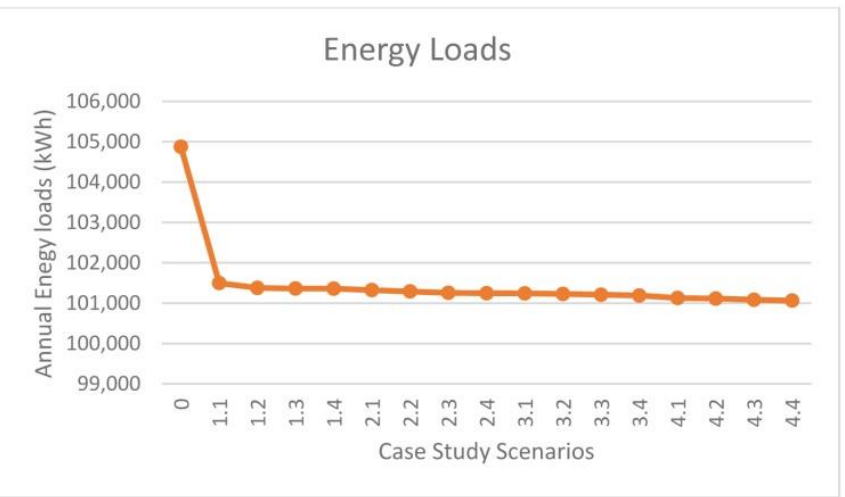

Fig. 10. Energy loads results for the 16 case study scenarios. Source: Authors

TABLE III. SUMMARY OF ALL THE RESUlTS OF PHASE 1 SIMULATION. SOURCE: AUTHORS

\begin{tabular}{|c|c|c|c|c|c|}
\hline $\begin{array}{c}\text { Case } \\
\text { No. }\end{array}$ & $\begin{array}{c}\text { South } \\
\text { Angle }\end{array}$ & $\begin{array}{c}\text { East } \\
\text { Angle }\end{array}$ & $\begin{array}{c}\text { SDA } \\
(\%)\end{array}$ & $\begin{array}{c}\text { ASE } \\
(\%)\end{array}$ & $\begin{array}{c}\text { Energy Loads } \\
(\mathrm{kWh})\end{array}$ \\
\hline 0 & $\mathrm{~N} / \mathrm{A}$ & $\mathrm{N} / \mathrm{A}$ & 98.9 & 20.6 & $104,874.54$ \\
\hline 1.1 & $-15^{\circ}$ & $-15^{\circ}$ & 98.8 & 7.2 & $101,497.34$ \\
\hline 1.2 & $-15^{\circ}$ & $-20^{\circ}$ & 98.9 & 5 & $101,378.69$ \\
\hline 1.3 & $-15^{\circ}$ & $-25^{\circ}$ & 98.6 & 3.3 & $101,362.28$ \\
\hline 1.4 & $-15^{\circ}$ & $-30^{\circ}$ & 98.8 & 2.5 & $101,360.23$ \\
\hline 2.1 & $-20^{\circ}$ & $-15^{\circ}$ & 98.6 & 7 & $101,323.63$ \\
\hline 2.2 & $-20^{\circ}$ & $-20^{\circ}$ & 98.6 & 4.8 & $101,290.14$ \\
\hline 2.3 & $-20^{\circ}$ & $-25^{\circ}$ & 98.8 & 3.1 & $101,256.83$ \\
\hline 2.4 & $-20^{\circ}$ & $-30^{\circ}$ & 98.8 & 2.3 & $101,246.64$ \\
\hline 3.1 & $-25^{\circ}$ & $-15^{\circ}$ & 98.8 & 6.5 & $101,242.38$ \\
\hline 3.2 & $-25^{\circ}$ & $-20^{\circ}$ & 98.8 & 4.3 & $101,227.81$ \\
\hline 3.3 & $-25^{\circ}$ & $-25^{\circ}$ & 98.8 & 2.6 & $101,209.15$ \\
\hline 3.4 & $-25^{\circ}$ & $-30^{\circ}$ & 98.6 & 1.8 & $101,190.73$ \\
\hline 4.1 & $-30^{\circ}$ & $-15^{\circ}$ & 98.9 & 6.5 & $101,127.88$ \\
\hline 4.2 & $-30^{\circ}$ & $-20^{\circ}$ & 98.9 & 4.3 & $101,115.22$ \\
\hline 4.3 & $-30^{\circ}$ & $-25^{\circ}$ & 98.6 & 2.4 & $101,084.33$ \\
\hline 4.4 & $-30^{\circ}$ & $-30^{\circ}$ & 98.5 & 1.6 & $101,065.93$ \\
\hline
\end{tabular}

The best results for each metric are highlighted in orange and the worst value for each metric is highlighted in grey.

\section{B. Phase 2 Results:}

The second phase calculates the amount of energy generated from the PV panels in each façade differing according to the tilt angles. The south façade bypassed the east façade generation for all the applied PVSD tilt angles. The ($30^{\circ}$ ) tilt angle of the shading device achieves the highest exposure to solar radiation thus, achieves the highest energy generation potential reaching an annual production of 7275 $\mathrm{kWh}$. This huge amount is generated from one space only in one floor of the building, revealing the great potential of energy generation using such systems. The worst PVSD tilt angle on the south façade is $\left(-15^{\circ}\right)$ from the horizontal which generates around $7056 \mathrm{kWh}$. On the other hand, for the east façade, the highest generation is achieved by the $\left(-15^{\circ}\right)$ tilt angle reaching $6417 \mathrm{kWh}$ while the lowest generation is done by the $\left(-30^{\circ}\right)$ tilt angle.

This could be explained by the higher angle of sunrays in the southern façade, so the incident solar radiation on the PVSD mounted on the southern facades is higher than that on 
the eastern one. The higher energy generation in the south façade proves the known fact that it is best to orientate the PVSDs to the direction perpendicular to the hemisphere where the location is in. Accordingly, for Egypt being in the northern hemisphere, the south direction is expected to be the best for its maximum exposure to solar radiation and minimum shading from the surrounding context. However, what is noteworthy is the extent of generation gained from the East façade that is usually overlooked in literature. It represents around $88 \%$ of that achieved by the south-oriented PVSDs which is not a big difference proving a great potential for the east-oriented PVSDs as well.

Electricity generated from the optimum scenario based on phase one analysis could be estimated to be $7275.7 \mathrm{kWh}$ in addition to $6253.5 \mathrm{kWh}$ totaling $13,429.2 \mathrm{kWh} /$ year from these PVSDs.

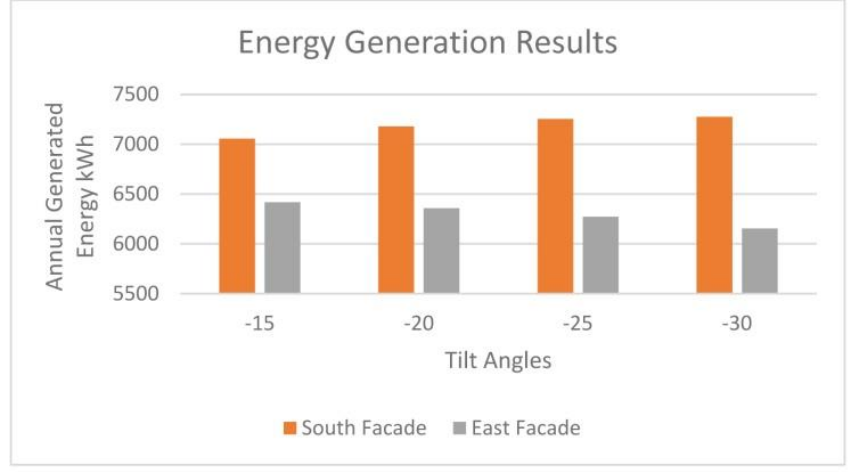

Fig. 11. Energy generation results for different orientations and tilt angles. Source: Authors

TABLE IV. ANNUAL ENERGY GENERATED By PVSD IN EACH FACADE. SOURCE: AUTHORS

\begin{tabular}{|l|c|c|c|c|}
\hline Tilt Angle $\left({ }^{\circ}\right)$ & $-15^{\circ}$ & $-20^{\circ}$ & $-25^{\circ}$ & $-30^{\circ}$ \\
\hline South DC (kWh) & 7056.1 & 7179.07 & 7254.1 & 7275.7 \\
\hline North DC (kWh) & 6417.3 & 6357.5 & 6271.16 & 6153.5 \\
\hline
\end{tabular}

\section{CONCLUSION}

Solar energy potential in Egypt is an undeniable fact, accordingly; all methods that can make use of this potential to generate electricity must be subject to excessive studying and evaluation. This paper chose to join the discussion on the potential of BIPV systems in the Egyptian context. It specifically focused on the PVSD systems being seen as extremely promising when it comes to retrofitting strategies for already existing buildings. An educational building in the GUC University campus was studied to solve a real faced problem of excessive glare and overheating in summer due to its multi-oriented curtain wall facades. PVSDs were mounted on the south and east facades of one of the spaces at 4 different tilt angles $\left(-15^{\circ},-20^{\circ},-25^{\circ}\right.$ and $\left.-30^{\circ}\right)$ for each orientation. Results of the 16 case study scenarios showed that the case combining both $\left(-30^{\circ}\right)$ tilting on the two orientations rendered the best results when it comes to daylighting efficiency and glare reduction (ASE dropped greatly from 20.6 to 1.6 ) as well as for energy loads reduction.

The same angle also achieved the highest value of generated $\mathrm{kWh}$ in the southern façade reflecting being the optimum tilt angle in the studied range $\left(15^{\circ}\right.$ to $\left.30^{\circ}\right)$ that is assumed to be the most suitable for solar energy generation in the case of Cairo's lattitude. One important conclusion gained of conducting this paper is the overlooked potential of eastoriented PVSDs where it proved to generate almost $90 \%$ of that generated by the south-oriented ones, while in most studies the south façade is usually the tackled one. The paper also proved the huge impact that could be achieved for visual and thermal comfort improvement by just adding simple shading devices to the curtain walls; a rather easy to implement and feasible measure especially for retrofitting existing buildings.

\section{REFERENCES}

[1] Atwa, M. and Mohamed, A. (2017). Teaching Sustainability Between Building performance simulation and retrofitting and educational building facade. Young Energy Researchers Conference.

[2] Davies, M., El matbouly, S., El-Mazghouny, D., Schellekens, G. and Ahmad, S. (2015). Developing renewable energy projects A guide to achieving success in the Middle East. [online] Egypt: Eversheds Clean Energy Group. Available at: http://www.eversheds.com/energy [Accessed 1 Jun. 2016].

[3] El Zayat (2015), Solar energy introduction and PV-systems. Lecture

[4] Farrag, N. and Omran, S. (2017). Designing a building integrated photovoltaic system (BIPV) for residential façade: case study in egypt. ARPN Journal of Engineering and Applied Sciences, [online] VOL. 12, NO. 21(ISSN 1819-6608), pp.59916012. Available at: http://www.arpnjournals.org/jeas/research_papers/rp_2017/jeas_ 1117_6446.pdf [Accessed 10 Oct. 2018].

[5] Heschong, L., Wymelenberg, V.D., Andersen, M., Digert, N., Fernandes, L., Keller, A., Loveland, J., McKay, H., Mistrick, R., Mosher, B. and Reinhart, C., 2012. Approved Method: IES Spatial Daylight Autonomy (sDA) and Annual Sunlight Exposure (ASE) (No. EPFL-STANDARD-196436). IESIlluminating Engineering Society.

[6] Konis, K. and Selkowitz, S. (2017). The Role of Metrics in Performance-Based Design. Effective Daylighting with HighPerformance Facades, pp.33-100.

[7] Li, X., Peng, J., Li, N., Wang, M. and Wang, C. (2017). Study on Optimum Tilt Angles of Photovoltaic Shading Systems in Different Climatic Regions of China. Procedia Engineering, [online] 205, pp.1157-1164. Available at: https://ac.elscdn.com/S1877705817347410/ [Accessed 9 Oct. 2018].

[8] Marzouk, M. (2016). Rooftops from Wasted to Scarce Resource; The Competition between Harvesting Crops and Solar Energy in Nasr City, Cairo. MSc. thesis. Ain Shams University, Cairo and Stuttgart University, Germany.

[9] Solargis. (2016). Solar and PV data. [online] Available at: http://solargis.info/doc/ solar-and-pv-data\#GHI [Accessed 18 May 2016].

[10] USGBC (2014). "LEED v4 Daylight ", Retrieved 5/12/2014, 2014.

[11] Wymelenberg, K. and Mahić, A. (2018). Annual Daylighting Performance Metrics, Explained. [online] Archlighting.com. Available at: https://www.archlighting.com/technology/annualdaylighting-performance-metrics-explained_o [Accessed 10 Oct. 2018].

[12] Zhang, X., Lau, S., Lau, S. and Zhao, Y. (2018). Photovoltaic integrated shading devices (PVSDs): A review. Solar Energy, 170, pp.947-968. 
